Canadian

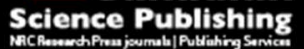

Canadian Journal of Civil Engineering Revue canadienne de génie civil

\title{
A Fuzzy Logic Approach to Posture-based Ergonomic Analysis for Field Observation and Assessment of Construction Manual Operations
}

\begin{tabular}{|r|l|}
\hline Journal: & Canadian Journal of Civil Engineering \\
\hline Manuscript ID & cjce-2015-0143.R1 \\
\hline Danuscript Type: & Article \\
\hline Complete List of Authors: & $\begin{array}{l}\text { Golabchi, Alireza; University of Alberta, Department of Civil and } \\
\text { Environmental Engineering } \\
\text { Han, SangUk; University of Alberta, Department of Civil and Environmental } \\
\text { Engineering } \\
\text { Robinson Fayek, Aminah; University of Alberta, Department of Civil and } \\
\text { Environmental Engineering }\end{array}$ \\
\hline Keyword: & $\begin{array}{l}\text { construction < type of paper to review, constr. management }< \\
\text { Construction, ergonomic assessment, construction health and safety }\end{array}$ \\
\hline
\end{tabular}




\title{
A Fuzzy Logic Approach to Posture-based Ergonomic Analysis for Field Observation and Assessment of Construction Manual Operations
}

\author{
Alireza Golabchi ${ }^{1}$, SangUk Han ${ }^{2}$, and Aminah Robinson Fayek ${ }^{3}$ \\ ${ }^{1}$ Ph.D. Student, Dept. of Civil and Environmental Engineering, Univ. of Alberta, 9105 116th St., \\ Edmonton, AB, Canada T6G 2W2. E-mail: alireza1@ualberta.ca \\ ${ }^{2}$ Assistant Professor, Dept. of Civil and Environmental Engineering, Univ. of Alberta, 9105 \\ 116th St., Edmonton, AB, Canada T6G 2W2. E-mail: sanguk@ualberta.ca \\ ${ }^{3}$ Professor, Dept. of Civil and Environmental Engineering, Univ. of Alberta, Edmonton AB, \\ Canada T6G 2W2. E-mail: aminah@ualberta.ca \\ Corresponding author: SangUk Han. Tel: 7804922722.
}




\begin{abstract}
In construction, workers are frequently exposed to ergonomic risks that can lead to musculoskeletal disorders. To prevent ergonomic injuries, proper assessment of ergonomic risk is a key to identifying risk factors and modifying work practice in a timely manner. In field observation, however, difficulties in visually estimating human postures (e.g., body joint angles) required for ergonomic analysis have led to inconsistent results due to the subjectiveness of observers. This study thus proposes a fuzzy logic approach to posture-based ergonomic evaluation tools. Rapid Upper Limb Assessment (RULA) is selected as a case study to describe the fuzzy logic modelling of RULA scoring systems and discuss the application to modular construction shops. The results of validation comparing correlations with biomechanical analysis - used as a ground truth - reveal that the proposed system produces more accurate results than traditional methods and hence helps minimize human errors in observation for reliable on-site ergonomic assessment.
\end{abstract}

\title{
Keywords
}

Ergonomic assessment, fuzzy logic, RULA, worker safety, work-related musculoskeletal disorder. 


\section{INTRODUCTION}

Construction activities are labour-intensive, with workers repeatedly exposed to physically challenging manual tasks involving forceful exertion and awkward postures. Such ergonomic risk factors (e.g., worker posture and motions, frequency and speed of work, and intensity and duration of exerted force) are primary causes of Work-related Musculoskeletal Disorders (WMSDs), i.e., injuries and disorders of muscles, tendons, and nerves (CCOHS 2014). Thus, the rate of work-related injuries and illnesses among construction workers is consistently reported to be high (Lopez and Gilkey 2014). For example, WMSDs (e.g., sprains and strains) account for $40 \%$ of all lost time claims (WSIB 2014) and for about $47 \%$ of all disabling injury claims in the construction industry in Canada (OHS 2012). WMSDs also impose substantial costs to employers due to lost productivity resulting from absenteeism, as well as increased health care, disability, and workers' compensation costs. The annual cost of WMSDs to the Canadian economy, including direct and indirect costs, is estimated to be $\$ 20$ billion (McGee et al. 2011). The leading source of ergonomic injuries is reported to be the workers themselves (i.e., bodily motion or posture) (WSIB 2014), implying that modifying the postures and movements of workers or modifying workplaces to accommodate workers can significantly contribute to decreasing the rate of WMSDs.

Appropriate and efficient ergonomic assessment is critical in efforts to mitigate the ergonomic risks involved in worker movements and eventually to reduce the rate of WMSDs. In order to enable proactive risk assessment and control in a jobsite, practitioners and researchers have developed different approaches: self-evaluation, observation-based methods, and direct measurements (Li and Buckle 1999). Self-evaluation methods use self-reports from workers to obtain information regarding physical and psychosocial factors through diaries, interviews, and 
questionnaires. Observational methods involve an ergonomist or task analyst observing working postures and actions in real time or from recorded video in order to identify unsafe motions and take corrective measures (NIOSH 2014). This type of evaluation is performed using ergonomic assessment tools which assign scores to manual tasks based on body posture, task repetitiveness, and duration. Examples of widely-used tools include Rapid Upper Limb Assessment (RULA) (McAtamney and Corlett 1993), Rapid Entire Body Assessment (REBA) (Hignett and McAtamney 2000), NIOSH lifting guideline (Waters et al. 1993), and Strain Index (SI) (Moore and Garg 1995). The observation-based methods are used in construction to evaluate the ergonomic risks of human motions that are recorded to build digitalized skeleton models in a virtual environment (Golabchi et al. 2015). Direct measurement methods involve using monitoring instruments such as sensors to obtain more precise information about body postures (e.g., range of joint motions) or forces exerted on body parts (e.g., hands), which can later be evaluated using ergonomic tools. For instance, Gatti et al. (2011) have investigated the use of Physiological Status Monitors (PSMs) to assess their efficiency in monitoring construction workers' physical strains, and Ray and Teizer (2012) have focused on worker posture estimation using range cameras. Alwasel et al. (2011) have studied the application of magneto-resistive sensors to measure body joint angles, and Han and Lee (2013) have developed a computer vision-based approach to extract construction workers' motion data from video to identify unsafe actions.

Among the three ergonomic risk analysis approaches, observation-based methods (i.e., manual observation using ergonomic assessment tools) have been the most widely implemented in practice due to their simplicity, validity, accessibility, and cost- and time-efficiency (NIOSH 2014; Chiasson et al. 2012; Bao et al. 2007; Takala et al. 2010; Kee and Karwowski 2007). Self- 
evaluation methods are generally less accurate and reliable compared to the other methods (David 2005). On the other hand, despite the potentially higher accuracy of the direct measurement techniques, their use still remains challenging due to technology and resource limitations; for example, they are usually applied to small population samples, where postures with only limited number of joints can be measured simultaneously (Bao et al. 2007). Furthermore, the accuracy of these technologies is highly affected by the jobsite conditions (e.g., outdoor construction), and some types of sensors (e.g., wearable sensors) limit the worker's ability to freely perform their regular tasks and may result in discomfort. Furthermore, direct measurement techniques are generally used to obtain joint angle values describing a posture that would later be analyzed using existing ergonomic assessment tools. In this regard, ergonomic assessment tools serve as a key to properly identifying and evaluating onsite ergonomic risks associated with human postures.

In field observation, however, the reliability of ergonomic evaluation results is contingent upon manual measurement of inputs required for the assessment tools (e.g., body joint angles, moving distances). The visual ambiguity in estimating those inputs often makes it difficult for a human observer to obtain accurate inputs, leading to inaccurate analysis outcomes. Consequently, the accuracy of evaluation results and derived risk intervention plans is inherently affected by the subjectiveness towards the evaluator's inputs. In an effort to address this issue, this study proposes a fuzzy logic-based framework to deal with the imprecision of ergonomic assessment inputs caused by human intuition in field observation. This framework involves remodelling the scoring systems of an ergonomic tool. This paper first reviews existing ergonomic assessment tools and discusses the issues pertaining to the impact of input errors on analysis results. Then, the proposed ergonomic model is presented and validated by comparing the results 
of the existing tool and proposed model with the results obtained from biomechanical analysis. Biomechanical analysis enables the identification of ergonomic risks by evaluating the internal loads imposed on the human body's joints and is thus regarded as an objective assessment method. A case study in which the proposed model is applied to modular construction is also carried out, and the contributions and limitations of the study are discussed based on the results.

\section{TRADITONAL ERGONOMIC ASSESSMENT TOOLS}

Ergonomic posture analysis is performed using assessment models and checklists in order to evaluate the safety risks involved in human actions by calculating overall scores indicating the level of risk associated with a manual task. This approach considers human postures as well as external risk factors such as task frequency and duration in order to provide a global risk assessment (i.e., ergonomic risks imposed on the human body) associated with a posture. The assessment systems typically require inputs pertaining to the posture of the worker (e.g., body joint angles), the load being handled by the worker (e.g., weight of object being carried), and the frequency of the task (e.g., static, repeated). Using this set of inputs, the level of ergonomic risks associated with a manual task is estimated. These assessment tools typically define discrete boundaries between ranges of input variables (e.g., body joint angle), where inaccurate human perception can lead to discrepancies in the analysis results when an observer fails to clearly distinguish the input values close to boundaries. Considering the imprecision of the inputs, this discrepancy can yield unreliable ergonomic evaluation results. Table 1 shows six of the widely used posture-based ergonomic assessment tools, as well as the inputs with discrete boundaries for each.

[Table 1: Example of inputs with discrete boundaries in ergonomic assessment tools] 
One of the cases with the highest imprecision of inputs in field observation occurs in estimating body joint angles, as required for posture-based ergonomic assessment tools (e.g., RULA, REBA, LUBA). Since joint angles are the main inputs for such assessment methods, the perception issue on angles close to border ranges can highly affect the accuracy and reliability of the final results. This study focuses on the RULA method as a case study based upon which to discuss the human perception issue with respect to posture estimation, as well as to describe the proposed fuzzy logic approach to ergonomic analysis.

\subsection{Rapid Upper Limb Assessment (RULA)}

RULA is widely accepted as an effective ergonomic assessment method due to its simplicity and precision in assessing posture-related loads (Levanon et al. 2014; Kee and Karwowski 2007). It is developed to provide a quick way to assess the exposure of workers to ergonomic risk factors by examining ergonomic risks imposed on the human body (McAtamney and Corlett 1993). The assessment is focused on the neck, trunk, shoulder, and upper limbs, which are the most relevant body sections in many types of work with a high rate of WMSDs, including construction tasks (Takala et al. 2010). In RULA, each body segment is considered independently and a corresponding score is calculated for the body part based on its posture. For each body segment (i.e., upper arm, lower arm, wrist, neck, and trunk), the ergonomist assigns the posture to one of the categories proposed by RULA and obtains the corresponding score for that body part. The final score, which represents the level of risk, is then obtained by combining the scores of different body segments.

RULA also considers the frequency of the task (i.e., muscle use) and the force exerted on the worker's body. The scores of different body segments are combined with the muscle use and force scores and a final score between 1 and 8 is obtained. Lower scores represent ergonomically 
acceptable postures with very low risk of injury and higher scores indicate exposure to immediate risk and the need for prompt investigation and modifications.

\subsection{Human Perception Issue in RULA}

The RULA method has been validated by McAtamney and Corlett (1993), who conducted an experiment in an ergonomics laboratory environment by analyzing subjects performing a data entry operation. The experiment aimed to investigate whether RULA scores appropriately reflect the musculoskeletal loads corresponding to the test subjects' reports of pain, ache, or discomfort in the relevant body part. The Chi-Square $\left(\mathrm{X}^{2}\right)$ statistical test was used to determine the association between RULA score and any reported pain, ache, or discomfort, and a highly significant association $(\mathrm{P}<0.01)$ was reported. In order to test RULA's reliability, over 120 ergonomists and engineers were trained to assess motions of operators and workers using RULA. A high consistency in RULA scores was found among the subjects.

However, discrepancies occurred in cases where the posture consisted of a body part being located at a border between two ranges (McAtamney and Corlett 1993). Although the ranges of lower arm were modified from the original version in order to mitigate this discrepancy, the issue still remains for any posture with body segments close to the border of ranges. While observing a worker motion in order to evaluate it using an ergonomic assessment tool such as RULA, the evaluator inputs the body segment angles based on approximate estimates rather than precise values. However, the RULA system proposes discrete boundaries between the angle ranges for the different body parts. This results in discrepancies in the RULA results for postures involving body segments close to the angle borders.

For example, three different postures are created for comparison in a 3D modelling environment with exact values of joint angles (Fig. 1). Table 2 shows the three sets of inputs for 
the RULA method and the resulting RULA score for each. Considering posture I and posture II, it can be observed that, although many of the angles and also the exerted force are considerably different, the final RULA score is the same. On the other hand, inputs of posture II and posture III have very close values, making it difficult for an observer to choose between the two, while the RULA score is substantially different. The sharp boundary between the upper arm angle ranges of $20^{\circ}$ to $45^{\circ}$ and $45^{\circ}$ to $90^{\circ}$ in Fig. 2 indicates that an upper arm angle of $44^{\circ}$ will result in an upper arm score of +2 , while an upper arm angle of $46^{\circ}$ results in an upper arm score of +3 . Consequently, the total RULA score and corrective plan of action will be different for these two postures. This discrepancy occurs due to the inputs selected being close to the border of angle ranges.

[Fig. 1. Postures corresponding to data in Table 2]

[Table 2. RULA scores for three sets of inputs]

For further analysis, Fig. 2 shows the change in the RULA Arm \& Wrist score, when lower arm and wrist angles remain fixed and the upper arm angle changes from $-90^{\circ}$ to $180^{\circ}$. As shown in the chart, the discrete boundaries between angle ranges results in sudden change of score at border angles (e.g., $-20^{\circ}, 20^{\circ}$ ). Considering the imprecision of inputs caused by human perception, a gradual transition between the scores, rather than an abrupt change, will improve the accuracy of the method. Since RULA is being widely used as an efficient ergonomic assessment tool, this study aims to improve its reliability by addressing the issue of discrepancy at postures with inputs close to borders of ranges. 
[Fig. 2. The impact of upper arm posture categories on intermediate results of Arm \& Wrist score: (a) Upper arm posture categories of RULA, and (b) abrupt change in RULA Arm \& Wrist score corresponding to change in upper arm angle]

\section{RESEARCH FRAMEWORK}

This research leverages fuzzy logic techniques to model ergonomic assessment tools as fuzzy expert systems. Fuzzy logic is an effective way to deal with imprecise and uncertain information and reason with ambiguous concepts, as it enables gradual transition between different classes of continuous variables with unsharp boundaries (Zadeh 1975). Thus, the imprecision of the inputs of ergonomic assessment systems (i.e., body joint angles) and the sharp boundary between the posture classifications (i.e., angle ranges) can be incorporated into fuzzy logic modelling processes to minimize the human perception issue in estimating joint angles. In the case of posture-based assessment systems, the use of fuzzy logic thus enables a steady transition between the scores of different angle ranges of body joints, which results in gradual transition of corresponding scores. This approach improves the reliability of ergonomic assessment methods by overcoming the limitation of abrupt changes in scores. A fuzzy expert system, Fuzzy RULA, is developed based on RULA. Fuzzy RULA requires the same set of inputs as RULA (e.g., body joint angles, load) and outputs a total assessment score. The performance of the model is assessed by investigating its correlation with RULA as well as with biomechanical analysis results, used as a ground truth in this research. The correlation between RULA and biomechanical analysis is also calculated in order to compare the performance between Fuzzy RULA and RULA. A sensitivity analysis is then carried out in order to find the system configuration resulting in the highest accuracy. The proposed approach is implemented in a construction jobsite to further examine its effectiveness and applicability. 


\subsection{Fuzzy RULA Model Development}

Fuzzy logic is a mathematical tool developed to deal with reasoning that is approximate rather than precise (Zadeh 1965). Due to the subjective uncertainty inherit in construction operations and decision making processes, fuzzy logic techniques have been increasingly used in many applications such as construction knowledge discovery systems (Elwakil and Zayed 2014), benchmarking knowledge management of construction firms (Kale and Karaman 2011), contractor default prediction (Awad and Fayek 2012), risk assessment (Li et al. 2013; Nasirzadeh et al. 2008), and quality assessment of infrastructure projects (Fayek and Rodriguez Flores 2010). For the modelling of subjectiveness, a fuzzy expert system uses a collection of fuzzy membership functions and if-then rules to imitate the thinking process of an expert and reason about data. The rule's antecedent defines the extent to which the rule applies using membership functions, and the conclusion assigns a membership function to the output variables. The inference process starts with assigning membership grades to the inputs based on the premises of the rules, known as fuzzification. The membership degrees in the rule's premise are then combined, typically using minimum or product operators, which is known as inference. The fuzzy subsets assigned to each output variable are then combined, usually using s-norm operators, to form a single fuzzy subset in a process known as aggregation. Finally, the fuzzy output set is converted to a crisp number through defuzzification. The basic configuration of a fuzzy logic system is shown in Fig 3.

[Fig. 3. Configuration of a fuzzy logic system] 
The RULA-based fuzzy model developed in this study consists of a fuzzy expert system with 9 inputs, 4 intermediate variables, 1 final output, 5 rule blocks, 114 membership functions, and 371 if-then rules. The structure of the model is shown in Fig. 4.

[Fig. 4. Structure of the Fuzzy RULA expert system]

In Fuzzification (Fig. 3), membership functions are curves that describe the evaluation criteria for inputs and outputs of the fuzzy expert system. They are used to map input values to a degree of membership in the fuzzy set. Membership degrees indicate the degree of belonging of a value to different terms and range from 0 to 1 , with 0 representing non-membership and 1 representing full membership. Developing membership functions is a crucial but also challenging step in developing a fuzzy expert system. Membership functions can be developed using different techniques that can be categorized as discrete representation and continuous functional form representation (Dissanayake and Fayek 2007). Examples of discrete representation include pairwise comparison, direct assignment, and exemplification. Examples of continuous functional form representation consist of heuristically-based, statistically-based, and cluster-based methods (Poveda and Fayek 2009).

In this study, a heuristic method is used to develop the membership functions for the input and output variables. As a base case, trapezoidal membership functions are used to represent the angle ranges of the inputs as well as the force imposed on the worker, and triangular membership functions are used for intermediate variables which represent the RULA intermediate scores. The final output variable, RULA total score, is also represented by triangular membership functions. Triangular and trapezoidal membership functions are used due to efficiency of the computation involved, simplicity of application and understanding for different users, and high frequency of use in fuzzy logic modelling (Poveda and Fayek 2009). The overlap between adjacent 
membership functions is designed such that the point of intersection has a membership degree of 0.5, which enables gradual transition between variables. The point of intersection for the input variables is the border angle between two angle ranges for joint angle inputs and the border force for the load/force input variable, as shown in Fig. 5. For intermediate and output variables, the core point of each membership function corresponds to the score that the curve represents.

[Fig. 5. Example of point of intersection for upper arm input variable]

In Rule Evaluation (Fig. 3), fuzzy expert systems contain a set of if-then rules which define the logical reasoning that relates the input variables to the output variables. The condition part of a rule is represented by membership functions of the input variables, and the conclusion part is represented by membership functions of the output or intermediate variables. The basis of the ifthen rules for the Fuzzy RULA model are the three scoring tables of the RULA system. Fig. 6 shows the scoring table for neck, trunk, and leg score (McAtamney and Corlett 1993), as well as an example of a rule derived from the table.

After rule aggregation and as the final step (Defuzzification in Fig. 3), membership functions of the output (i.e., RULA total score) are used to obtain a crisp value representing the final score. Defuzzification is the inverse process of fuzzification, where, based on the given fuzzy sets of the output and calculated degrees of membership, a defuzzification method (e.g., centroid, bisector, smallest of maximum) is used to select the most accurate quantifiable representation of the output. The total Fuzzy RULA score obtained from this step defines the level of ergonomic risk associated with the input posture based on the RULA interpretation of final scores.

[Fig. 6. Neck, Trunk, \& Leg score table and example of an if-then rule]

\subsection{Results and Validation}

Page 13 of 34

https://mc06.manuscriptcentral.com/cjce-pubs 
In order to validate the Fuzzy RULA model, a two-step validation process is carried out. The first step is to ensure that Fuzzy RULA has a high correlation with the RULA method. The second step involves validating that Fuzzy RULA is a more accurate representation of the loads exerted on the worker's body than is RULA. The base case of the Fuzzy RULA expert system is developed using triangular and trapezoidal membership function shapes, the minimum t-norm operator for combining the input variables, the product operator for implication of the combined input to the output in each rule, the maximum s-norm operator for the aggregation of the rules, and the Center of Maximum (CoM) method as the defuzzification method.

\subsubsection{Correlation between RULA and Fuzzy RULA}

In order to study the correlation between RULA and Fuzzy RULA, a correlation analysis is performed using the Spearman's rank correlation coefficient (Spearman 1904). The Spearman's rank correlation coefficient, also known as Spearman's rho $(\rho)$, is a nonparametric measure of statistical dependence between two variables. It is a measure of the dependence between two variables, giving a value between +1 and -1 , where 1 is total positive correlation, 0 is no correlation, and -1 is total negative correlation. In order to detect a simple correlation $(\mathrm{r}=0.5)$ of $\mathrm{N}$ observations with a $5 \%$ significance level $(\alpha=0.05)$ test and $80 \%$ power $(\beta=0.2)$, the required sample size is 29 (Lachin 1981). Thus, 29 random input data sets (joint angles, muscle use, and force) are generated, and the RULA score and Fuzzy RULA score are calculated for each data set. As a result, a Spearman's rank correlation coefficient of 0.833 is calculated between the two sets of scores, which indicates strong correlation (Mukaka 2012) between the RULA system and Fuzzy RULA.

\subsubsection{Correlation between Fuzzy RULA and biomechanical analysis}


Biomechanical analysis is the study of human motion as a function of body structure in order to identify and prevent causes of injuries through the assessment of internal loads on the human's joints in order to analyze musculoskeletal stresses on the joints at risk (Armstrong et al. 1996). Biomechanical models enable estimating internal forces imposed on body joints that cannot be easily measured by describing the complex musculoskeletal systems of the body (Chaffin 2008). Since biomechanical analysis provides an objective assessment of ergonomic risks associated with a posture, the correlation between the Fuzzy RULA model and biomechanical analysis is investigated in order to further study the Fuzzy RULA model's reliability. This correlation is compared with the correlation between the RULA method and biomechanical analysis in order to compare the accuracy of the Fuzzy RULA model with RULA. To this end, the 3DSSPP software (Chaffin et al. 2006) is used to assess the loads imposed on the body joints, and the compression load on the human's back is selected to reflect the biomechanical forces associated with a posture. The 3DSSPP software enables evaluating postures by inputting angle values for the different body segments as well as forces exerted on the hands into the analysis environment.

In order to perform correlation analysis, the low back compression for each of the 29 postures is extracted from 3DSSPP. Spearman's correlation analysis is performed between the low back compression and the corresponding Fuzzy RULA scores, and a correlation coefficient of 0.710 is calculated. Furthermore, a correlation coefficient of 0.508 is calculated between the low back compression and posture scores obtained from the RULA method. The results indicate that RULA holds a moderate correlation with the result of biomechanical analysis (i.e., low back compression), while there is a strong correlation between Fuzzy RULA and biomechanical analysis.

\subsubsection{Sensitivity Analysis}


A sensitivity analysis is carried out by varying the parameters of the base case model in order to determine the configuration yielding the highest accuracy. The parameters changed during the analysis include shape of membership functions (linear and s-shape), input aggregation methods (minimum, product, minimum/maximum, and minimum/average), rule aggregation methods (maximum and bounded sum), and defuzzification methods (center of maximum, middle of maximum, fast center of area, and hyper center of maximum). In total, 64 cases are developed, and for each case the Spearman's correlation coefficient between Fuzzy RULA and biomechanical analysis is calculated for the 29 random postures. The most accurate configuration consists of triangular and trapezoidal shaped membership functions, minimum operator for input aggregation, product operator for rule implication, bounded sum operator for rule aggregation, and fast center of area for defuzzification method. A Spearman correlation coefficient of 0.713 is calculated for this configuration. Table 3 shows the result of the sensitivity analysis for the 32 cases of linear membership function.

[Table 3. System configurations for sensitivity analysis]

\section{CASE STUDY: APPLICATION IN MODULAR CONSTRUCTION}

A case study is carried out to illustrate the application of these procedures in practice in order to further validate the fuzzy system with motion datasets obtained from an actual site. This case study also provides a context for discussing the motivation for this study from a practical perspective. In this case study, the developed fuzzy expert system is used to assess the ergonomic risks associated with manual activities in a production line of a construction modular prefabrication company. Data regarding manual handling tasks are collected from the jobsite in 
order to perform RULA and Fuzzy RULA assessments as well as biomechanical analysis. The Spearman's correlation is then used to investigate the association between the results.

Off-site modular construction is considered an efficient construction method which is environmentally-friendly, entails a shorter completion time, and effectively facilitates quality and cost control. Despite technological advances in the construction and manufacturing industries, workers in off-site construction perform labour-intensive and physically demanding tasks, resulting in high rates of work-related accidents and injuries. This study implements the developed framework in a construction fabrication shop setting; it can be similarly applied to other types of construction jobsites. In this case study, the manual tasks involved in the process of building floor panels in the fabrication shop are investigated; this study builds on the case study initially conducted in Golabchi et al. (2015), which is summarized as follows. The sequence of the activities starts with delivering timbers to the nailing workstation where they are nailed together. The pieces are then nailed to sheathing to form the floor panels. These floor panels are transferred to the cutting workstation where openings are added. This process consists of twelve different manual tasks in total. Motion data of these manual tasks are collected in order to obtain the required input for the RULA, Fuzzy RULA, and biomechanical analysis. Specifically, videos of each of the manual activities are recorded from the jobsite and analyzed in order to build the corresponding motion data for each activity in a $3 \mathrm{D}$ environment representing the jobsite. This process is carried out in order to link ergonomic analysis with $3 \mathrm{D}$ virtual modelling, which enables analyzing and improving human motions in an interactive manner. In order to build the 3D virtual model, data pertaining to the layout of the jobsite, dimensions of the different material and equipment involved, and processing times of the tasks are collected from the jobsite. Also, worker anthropometry data and weights of tools and materials are collected to 
ensure accurate representation of the worker models and motions for ergonomic analysis purposes. For example, data regarding the tools used by the workers (e.g., nail gun) are collected to compute the loads imposed on the workers during the manual tasks. The data are gathered by obtaining all available blueprints and specifications of the production line as well as visual inspection of the jobsite to ensure the accuracy of the $3 \mathrm{D}$ virtual environment, which is also reviewed and verified by the facility management personnel. After creating the 3D virtual model in Autodesk 3ds Max, each worker's motion data are extracted in a motion capture data format, such as the Biovision Hierarchy $(\mathrm{BVH})$ format. From the motion datasets extracted from the virtual model, awkward postures are identified, and the joint angle values for each posture are obtained automatically by computing the body joint angles at each time frame from the BVH format datasets. These angle values are then used as inputs to perform RULA, Fuzzy RULA, and biomechanical analysis as described above. Table 4 shows the twelve tasks and the results of the RULA and Fuzzy RULA analysis, as well as the back compression associated with each task from the biomechanical analysis.

[Table 4. Results of ergonomic analysis of manual activities in the production line]

A Spearman correlation coefficient of 0.930 is calculated between the Fuzzy RULA results of the twelve tasks and the corresponding back compressions, while a Spearman coefficient of 0.765 is calculated between the RULA results and the results of biomechanical analysis. A correlation coefficient of 0.832 is also calculated between the RULA and Fuzzy RULA results. The results of the case study are consistent with the results of the validation section, confirming the higher reliability of the Fuzzy RULA system in analyzing worker motions from actual jobsites. 
For biomechanical analysis, significant time and effort are required to build motion models of workers, compared to observation-based ergonomic assessment tools such as RULA. Unlike the observation-based methods, biomechanical analysis systems are not generally used in a field setting to observe and analyze a worker in real time, since detailed posture information (e.g., angles at most critical body joints) is required. The high correlation between Fuzzy RULA and biomechanical analysis (i.e., 0.930) indicates that occupational health and safety practitioners can rely on the results of the Fuzzy RULA model without the need to go through further biomechanical analysis to verify the results of ergonomic analysis. This facilitates incorporation of ergonomic analysis by construction practitioners in the daily operations, which will result in lower rates of WMSDs.

\section{DISCUSSION}

The Fuzzy RULA model as proposed in this paper achieves a correlation of 0.713 with biomechanical analysis results through validation with random postures, and a correlation of 0.930 in using worker postures collected from a construction jobsite. These correlations are higher than the corresponding correlations of traditional RULA (0.508 for random postures and 0.765 for jobsite postures). These results imply that the fuzzy logic approach to ergonomic analysis is capable of dealing robustly with human perception issues, particularly those occurring at close-to-border angles in ergonomic methods. Thus, the proposed fuzzy expert system addresses the issue of discrepancy of ergonomic analysis results when analyzing body postures with body joint angles close to borders of angle ranges defined by the ergonomic assessment tools. Since workers in the construction industry perform various manual activities involving unique postures, this paper provides a precise, reliable, and efficient ergonomic assessment method that can be used to analyze ergonomic risk in a field setting. 
There are several potential limitations which further investigation is required in order to address. First, it should be noted that this paper focuses solely on RULA. The proposed fuzzy expert system can be applied in a similar manner to other types of posture-based ergonomic evaluation methods (e.g., REBA, LUBA), as they require similar types of inputs to RULA but only differ in the number of posture categories or in the body parts to be observed. Nevertheless, the membership functions and model parameters selected in this paper may differ from other tools that define the varying input boundaries. The boundaries set differently may affect human cognitive systems in recognizing and distinguishing human postures. Thus, understanding of human perception is required in order to properly determine fuzzy logic parameters and membership functions.

Second, other types of ergonomic assessment methods require different inputs (e.g., horizontal multiplier in NIOSH lifting equation in Table 1) rather than human postures. In this case, each boundary of inputs can range narrowly, thereby resulting in a large number of membership functions being set. Other types of inputs, such as frequency and duration, may not have linear relationships with the final score. Such cases require further investigation of the impact of input variances on the output and thorough verification of fuzzy logic modelling through the comparison with objective measures of ergonomic risk (e.g., biomechanical analysis).

Third, this study uses low back compression imposed on the human body as the measure of level of ergonomic risks from the results of biomechanical analysis. Although the back is the most commonly injured body part in ergonomic injuries (Work Safe Alberta 2012), it should be noted that an increase in the RULA or Fuzzy RULA score does not always result in a corresponding increase in the lower back compression. This is due to the fact that the methodology for identifying the level of risks is different in the two approaches, and the results 
of the ergonomic evaluation methods also focus on the loads exerted on other body joints. This study only used the back compression from biomechanical analysis as it more appropriately reflects the ergonomic risks compared to other body parts. In future research, additional results of biomechanical analysis, including forces exerted on other body joints, will be extracted and used for correlation analysis to achieve more comprehensive results.

In addition, the Fuzzy RULA expert system, in its current format, requires discrete angle and force values as inputs and produces a final RULA score in a deterministic form. Although the imprecision inherit in estimating body angles of a posture is considered in the proposed model, the user still needs to select only one distinct value for each input (e.g., upper arm angle). Since ergonomists use approximate values as the joint angles in observation, inputting a range of angles instead of one discrete value may make the evaluation process more reliable by providing users with possible variations of the final scores. Ranges of the final output may represent the effect of potential human errors, thus assisting in appropriate decision making pertaining to the evaluation and mitigation of ergonomic risks. This approach will be further investigated in future study.

Future work will include application of fuzzy logic techniques to linguistic types of input variables for ergonomic analysis. For instance, Physical Demands Analysis (PDA) is another type of ergonomic assessment tools which enables quantifying the physical, psychological, and environmental demands of a manual task for proactive management of injury prevention or for retroactive assessment of injured workers in returning to work (IAPA 2009). This type of analysis is frequently used in practice and involves similar types of inputs such as frequency, force, and distance, which may cause the same imprecision of input estimation. This method utilizes linguistic variables to describe the severity of a physical activity in the observation 
processes. Thus, fuzzy logic approaches will be studied in order to better address the description of job conditions and requirements in evaluating the demands of a physical activity.

\section{CONCLUSION}

The continuous improvement of construction safety and health depends on the early identification of potential risk and timely mitigation of such at-risk conditions. Reliable assessment of ergonomic risk is essential in preventing WMSDs as ergonomic injuries are gradually developed over time. Toward this goal, this paper presents a fuzzy logic approach to ergonomic assessment in order to incorporate perception gaps in differentiating human postures into the evaluation mechanism of ergonomic methods. Case study results show that a fuzzy expert system for ergonomic evaluation outperforms the traditional method by addressing the issue of discrepancy of the results of traditional tools, caused by human perception with respect to discrete input boundaries. This study thus provides a more reliable field tool to identify and prevent unsafe worker postures in manual operations, and consequently reduce the rate of WMSDs in construction.

\section{ACKNOWLEDGEMENTS}

The authors wish to thank Dr. Mohamed Al-Hussein (University of Alberta) and his research group for their help in data collection for the case study section. The work presented in this paper was supported financially by the Natural Sciences and Engineering Research Council of Canada (NSERC). Any opinions, findings, and conclusions or recommendations expressed in this paper are those of the authors and do not necessarily reflect the views of NSERC.

\section{REFERENCES}


Alwasel, A., Elrayes, K., Abdel-Rahman, E.M., and Haas, C.T. 2011. Sensing construction work-related musculoskeletal disorders (WMSDs). Proceedings, International Symposium on Automation and Robotics in Construction and Mining (ISARC), Seoul, Korea, Jun. 29-Jul. 2.

Armstrong, T., Buckle, P., Fine, L., Hagberg, M., Haring-Sweeney, M., Martin, B., and Viikari-Juntura, E. 1996. Musculoskeletal disorders: Work-related risk factors and prevention. International Journal of Occupational and Environmental Health, 2(3): 239-246.

Awad, A., and Fayek, A. Robinson. 2012. Contractor default prediction model for surety bonding. Canadian Journal of Civil Engineering, 39(9): 1027-1042

Bao, S., Howard, N., Spielholz, P., and Silverstein, B. 2007. Two posture analysis approaches and their application in a modified Rapid Upper Limb Assessment evaluation. Ergonomics, 50(12): 2118-2136.

Canadian Centre for Occupational Health and Safety (CCOHS). 2014. What are workrelated musculoskeletal disorders (WMSDs) [online]. Available from http://www.ccohs.ca/oshanswers/diseases/rmirsi.html [accessed 25 February 2015].

Chaffin, D.B. 2008. Digital human models for workspace design. Reviews of Human Factors and Ergonomics, 4(1): 41-74.

Chaffin, D.B., Andersson, G.B., and Martin, B.J. 2006. Occupational Biomechanics, Fourth Edition, John Wiley \& Sons, Inc., Hoboken, NJ, USA.

Chiasson, M.È., Imbeau, D., Aubry, K., and Delisle, A. 2012. Comparing the results of eight methods used to evaluate risk factors associated with musculoskeletal disorders. International Journal of Industrial Ergonomics, 42(5): 478-488. 
David, G.C. 2005. Ergonomic methods for assessing exposure to risk factors for workrelated musculoskeletal disorders. Occupational Medicine, 55(3): 190-199.

Dissanayake, M., and Fayek, A. Robinson. 2007. Assigning membership in fuzzy set analysis for construction management applications. Proceedings, ASCE Construction Research Congress, Grand Bahamas Island, The Bahamas, 6-8 May 2007. American Society of Civil Engineers (ASCE), New York, NY, USA.

Elwakil, E., and Zayed, T. 2014. Construction knowledge discovery system using fuzzy approach. Canadian Journal of Civil Engineering, 42(1): 22-32.

Fayek, A. Robinson, and Rodriguez Flores, J.R. 2010. Application of fuzzy logic to quality assessment of infrastructure projects at conceptual cost estimating stage. Canadian Journal of Civil Engineering, 37(8): 1137-1147.

Gatti, U., Migliaccio, G., and Schneider, S. 2011. Wearable physiological status monitors for measuring and evaluating workers' physical strain: Preliminary validation. Computing in Civil Engineering: 194-201.

Golabchi, A., Han, S., Seo, J., Han, S., Lee, S., and Al-Hussein, M. 2015. "An Automated Biomechanical Simulation Approach to Ergonomic Job Analysis for Workplace Design.” Journal of Construction Engineering and Management, ASCE, 141(8), 04015020.

Han, S. and Lee, S. 2013. A vision-based motion capture and recognition framework for behavior-based safety management. Automation in Construction, 35: 131-141.

Hignett, S. and McAtamney, L. 2000. Rapid Entire Body Assessment (REBA). Applied Ergonomics, 31: 201-205. 
IAPA. 2009. Performing a physical demands analysis. Industrial Accident Prevention Association [online]. Available from http://www.iapa.ca/main/documents/pdf/freedownloads _pda_intro.pdf [accessed 6 March 2015].

Kale, S., and Karaman, E.A. 2011. A fuzzy logic model for benchmarking the knowledge management performance of construction firms. Canadian Journal of Civil Engineering, 38(4): $464-475$.

Kee, D., and Karwowski, W. 2001. LUBA: an assessment technique for postural loading on the upper body based on joint motion discomfort and maximum holding time. Applied Ergonomics, 32(4): 357-366.

Kee, D. and Karwowski, W. 2007. A comparison of three observational techniques for assessing postural loads in industry. International Journal of Occupational Safety and Ergonomics, 13(1): 3-14.

Lachin, J. 1981. Introduction to Sample Size Determination and Power Analysis for Clinical Trials. Controlled Clinical Trials, 2: 93-113.

Levanon, Y., Lerman, Y., Gefen, A., and Ratzon, N.Z. 2014. Validity of the modified RULA for computer workers and reliability of one observation compared to six. Ergonomics, 57(12): 1856-1863.

Li, G. and Buckle, P. 1999. Current techniques for assessing physical exposure to workrelated musculoskeletal risks, with emphasis on posture-based methods. Ergonomics, 42(5): $674-695$.

Li, H.X., Al-Hussein, M., Lei, Z., and Ajweh, Z. 2013. Risk identification and assessment of modular construction utilizing fuzzy analytic hierarchy process (AHP) and simulation. Canadian Journal of Civil Engineering, 40(12): 1184-1195. 
Lopez, C. and Gilkey, D. 2014. Injuries among construction workers: An exploratory study. Proceedings, 50th ASC Annual International Conference.

McAtamney, L., and Corlett, E.N. 1993. RULA: A survey method for the investigation of work-related upper limb disorders. Applied Ergonomics, 24: 91-99.

McGee, R., Bevan, S., and Quadrello, T. 2011. Fit for work? Musculoskeletal disorders and the Canadian labour market (Report 2). Ottawa: The Work Foundation, Conference Board of Canada.

Moore, S.J., and Garg, A. 1995. The strain index: a proposed method to analyze jobs for risk of distal upper extremity disorders. American Industrial Hygiene Association, 56(5): 443458.

Mukaka, M. 2012. A guide to appropriate use of correlation coefficient in medical research. Malawi Medical Journal, 24(3): 69-71.

Nasirzadeh, F., Afshar, A., Khanzadi, M., and Howick, S. 2008. Integrating system dynamics and fuzzy logic modelling for construction risk management. Construction Management and Economics, 26(11): 1197-1212.

NIOSH. 2014. Observation-based posture assessment: review of current practice and recommendations for improvement. By Lowe BD, Weir PL, Andrews DM. Cincinnati, OH: U.S. Department of Health and Human Services, Centers for Disease Control and Prevention, National Institute for Occupational Safety and Health, DHHS (NIOSH) Publication No. 2014131.

Occhipinti, E. 1998. OCRA: a concise index for the assessment of exposure to repetitive movements of the upper limb. Ergonomics, 41: 1290-1311. 
Occupational Health and Safety (OHS) (2012). Occupational injuries and diseases in Alberta: Lost-time claims, disabling injury claims and claim rates [online]. Available from http://work.alberta.ca/documents/2011-Occupational-Injuries-Diseases-Alberta-Summary.pdf [accessed 25 February 2015].

Poveda, C.A., and Fayek, A. Robinson. 2009. Predicting and evaluating construction trades foremen performance: Fuzzy logic approach. Journal of Construction Engineering and Management, 135(9): 920-929.

Ray, S.J. and Teizer, J. 2012. Real-time construction worker posture analysis for ergonomics training. Advanced Engineering Informatics, 26(2): 439-456.

Spearman, C. 1904. The proof and measurement of association between two things. American Journal of Psychology, 15(1): 72-101.

Takala, E.P., Pehkonen, I., Forsman, M., Hansson, G.Å., Mathiassen, S.E., Neumann, W. P., Sjøgaard, G., Veiersted, K.B., Westgaard, R.H., and Winkel, J. 2010. Systematic evaluation of observational methods assessing biomechanical exposures at work. Scandinavian Journal of Work, Environment \& Health, 36(1): 3-24.

Waters, T., Putz-Anderson, V., Garg, A., Fine, L. 1993 Revised NIOSH equation for the design and evaluation of manual lifting tasks. Ergonomics, 36: 749-766.

Work Safe Alberta. 2012. Occupational Injuries and Diseases in Alberta, Lost-Time Claims, Disabling Injury Claims and Claim Rates, 2011 Summary. Alberta Human Services [online]. Available from https://work.alberta.ca/documents/2011-Occupational-InjuriesDiseases-Alberta-Summary.pdf [accessed 10 October 2015]. 
WSIB. 2014. By the Numbers: 2013 WSIB Statistical Report-Schedule 1. Workplace $\begin{array}{lllll}\text { Safety } & \& & \text { Insurance } & \text { Board } & \text { [online]. Available }\end{array}$ http://www.wsibstatistics.ca/Schedule1/home.html [accessed 25 February 2015].

Zadeh, L.A. 1965. Fuzzy sets. Information and control, 8(3): 338-353.

Zadeh, L.A. 1975. The concept of a linguistic variable and its application to approximate reasoning-II. Information Sciences, 8(4): 301-357. 


\section{List of Tables}

Table 1. Example of inputs with discrete boundaries in ergonomic assessment tools.............................. 30

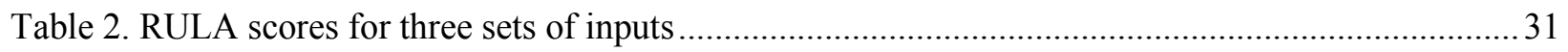

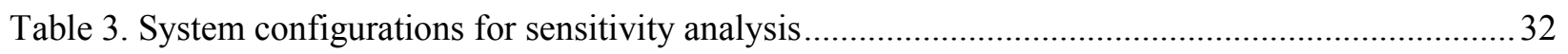

Table 4. Results of ergonomic analysis of manual activities in the production line ..................................33 
Table 1. Example of inputs with discrete boundaries in ergonomic assessment tools

\begin{tabular}{|c|c|c|c|}
\hline Method & $\begin{array}{l}\text { Inputs with discrete } \\
\text { boundaries }\end{array}$ & $\begin{array}{l}\text { Range of input } \\
\text { values }\end{array}$ & $\begin{array}{l}\text { Number of } \\
\text { input ranges }\end{array}$ \\
\hline \multirow{6}{*}{$\begin{array}{l}\text { RULA } \\
\text { (McAtamney and Corlett } \\
\text { 1993) }\end{array}$} & Upper arm & {$\left[\begin{array}{ll}-90^{\circ} & \left.180^{\circ}\right]\end{array}\right.$} & 5 \\
\hline & Lower arm & {$\left[0^{\circ} 180^{\circ}\right]$} & 3 \\
\hline & Wrist & {$\left[\begin{array}{ll}-90^{\circ} & 90^{\circ}\end{array}\right]$} & 4 \\
\hline & Neck & {$\left[\begin{array}{ll}-45^{\circ} & 90^{\circ}\end{array}\right]$} & 4 \\
\hline & Trunk & {$\left[\begin{array}{ll}60^{\circ} & 120^{\circ}\end{array}\right]$} & 4 \\
\hline & Load & $0 \mathrm{lb}-22^{+} \mathrm{lb}$ & 3 \\
\hline \multirow{7}{*}{$\begin{array}{l}\text { REBA } \\
\text { (Hignett and McAtamney } \\
\text { 2000) }\end{array}$} & Neck & {$\left[\begin{array}{ll}-45^{\circ} & 90^{\circ}\end{array}\right]$} & 3 \\
\hline & Trunk & {$\left[\begin{array}{ll}60^{\circ} & 120^{\circ}\end{array}\right]$} & 5 \\
\hline & Leg (adjustment) & {$\left[0^{\circ} \quad 180^{\circ}\right]$} & 3 \\
\hline & Upper arm & {$\left[\begin{array}{ll}-90^{\circ} & 180^{\circ}\end{array}\right]$} & 5 \\
\hline & Lower arm & {$\left[\begin{array}{ll}0^{\circ} & 180^{\circ}\end{array}\right]$} & 3 \\
\hline & Wrist & {$\left[\begin{array}{ll}-90^{\circ} & 90^{\circ}\end{array}\right]$} & 3 \\
\hline & Load & $0 \mathrm{lb}-22^{+} \mathrm{lb}$ & 3 \\
\hline \multirow{3}{*}{$\begin{array}{l}\text { The Strain Index } \\
\text { (Moore and Garg 1995) }\end{array}$} & Duration of exertion & $0 \%-100 \%$ & 5 \\
\hline & Efforts per minute & $0-20^{+} \min$ & 5 \\
\hline & Duration of task per day & $0-8^{+}$hours & 5 \\
\hline \multirow{5}{*}{$\begin{array}{l}\text { NIOSH Lifting Equation } \\
\text { (Waters et al. 1993) }\end{array}$} & Horizontal multiplier & 0 in $-25^{+}$in & 17 \\
\hline & Vertical multiplier & 0 in $-70^{+}$in & 16 \\
\hline & Distance multiplier & 0 in $-70^{+}$in & 13 \\
\hline & Asymmetric multiplier & {$\left[\begin{array}{ll}0^{\circ} & 135^{\circ}\end{array}\right]$} & 10 \\
\hline & Frequency multiplier & $0-8$ hours & 6 \\
\hline \multirow{3}{*}{$\begin{array}{l}\text { OCRA } \\
\text { (Occhipinti 1998) }\end{array}$} & Force multiplier factor & $0-1$ & 10 \\
\hline & Posture multiplier factor & $0-1$ & 5 \\
\hline & Recovery multiplier factor & $0-1$ & 8 \\
\hline \multirow{5}{*}{$\begin{array}{l}\text { LUBA } \\
\text { (Kee and Karwowski 2001) }\end{array}$} & Wrist & $0^{\circ}-60^{\circ+}$ & 3 \\
\hline & Elbow & $0^{\circ}-120^{\circ+}$ & 3 \\
\hline & Shoulder & $0^{\circ}-150^{\circ}$ & 4 \\
\hline & Neck & $0^{\circ}-45^{0^{+}}$ & 3 \\
\hline & Back & $0^{\circ}-60^{\circ+}$ & 4 \\
\hline
\end{tabular}


Table 2. RULA scores for three sets of inputs

\begin{tabular}{cccccccccccc}
\hline Posture Case & Upper Arm & $\begin{array}{c}\text { Lower } \\
\text { Arm }\end{array}$ & Wrist & $\begin{array}{c}\text { Wrist } \\
\text { Twist }\end{array}$ & Neck & Trunk & Leg & $\begin{array}{c}\text { Muscle } \\
\text { Use }\end{array}$ & $\begin{array}{c}\text { Force } \\
\text { RULA } \\
\text { score }\end{array}$ \\
\hline Posture I & $22^{\circ}$ & $65^{\circ}$ & $4^{\circ}$ & 2 & $11^{\circ}$ & $18^{\circ}$ & 2 & 0 & $5 \mathrm{lb}$ & 4 \\
Posture II & $44^{\circ}$ & $98^{\circ}$ & $14^{\circ}$ & 2 & $19^{\circ}$ & $18^{\circ}$ & 2 & 0 & $21 \mathrm{lb}$ & 4 \\
& & & & & & & & & & \\
Posture III & $46^{\circ}$ & $102^{\circ}$ & $16^{\circ}$ & 2 & $21^{\circ}$ & $22^{\circ}$ & 2 & 0 & $23 \mathrm{lb}$ & 7 \\
\hline
\end{tabular}


Table 3. System configurations for sensitivity analysis

\begin{tabular}{|c|c|c|c|c|c|c|}
\hline Scenario \# & $\begin{array}{l}\text { MF } \\
\text { shape }\end{array}$ & $\begin{array}{l}\text { Fuzzy } \\
\text { operator }\end{array}$ & $\begin{array}{l}\text { Inference } \\
\text { method }\end{array}$ & $\begin{array}{l}\text { Aggregation } \\
\text { method }\end{array}$ & $\begin{array}{l}\text { Defuzzification } \\
\text { method }\end{array}$ & $\begin{array}{l}\text { Spearman's } \\
\text { coefficient }\end{array}$ \\
\hline Base & Linear & MIN & PROD & MAX & COM & 0.709 \\
\hline 1 & Linear & PROD & PROD & MAX & $\mathrm{COM}$ & 0.651 \\
\hline 2 & Linear & MIN & PROD & BSUM & $\mathrm{COM}$ & 0.712 \\
\hline 3 & Linear & PROD & PROD & BSUM & $\mathrm{COM}$ & 0.711 \\
\hline 4 & Linear & MIN & PROD & MAX & MOM & 0.483 \\
\hline 5 & Linear & PROD & PROD & MAX & MOM & 0.483 \\
\hline 6 & Linear & MIN & PROD & BSUM & MOM & 0.579 \\
\hline 7 & Linear & PROD & PROD & BSUM & MOM & 0.628 \\
\hline 8 & Linear & MIN & PROD & MAX & Fast COA & 0.710 \\
\hline 9 & Linear & PROD & PROD & MAX & Fast COA & 0.651 \\
\hline 10 & Linear & MIN & PROD & BSUM & Fast COA & 0.713 \\
\hline 11 & Linear & PROD & PROD & BSUM & Fast COA & 0.711 \\
\hline 12 & Linear & MIN & PROD & MAX & Hyper COM & 0.710 \\
\hline 13 & Linear & PROD & PROD & MAX & Hyper COM & 0.651 \\
\hline 14 & Linear & MIN & PROD & BSUM & Hyper COM & 0.712 \\
\hline 15 & Linear & PROD & PROD & BSUM & Hyper COM & 0.711 \\
\hline 16 & Linear & MIN/MAX & PROD & MAX & $\mathrm{COM}$ & 0.424 \\
\hline 17 & Linear & MIN/AVG & PROD & MAX & $\mathrm{COM}$ & 0.596 \\
\hline 18 & Linear & MIN/MAX & PROD & BSUM & $\mathrm{COM}$ & 0.320 \\
\hline 19 & Linear & MIN/AVG & PROD & BSUM & COM & 0.523 \\
\hline 20 & Linear & MIN/MAX & PROD & MAX & MOM & 0.477 \\
\hline 21 & Linear & MIN/AVG & PROD & MAX & MOM & 0.483 \\
\hline 22 & Linear & MIN/MAX & PROD & BSUM & MOM & 0.290 \\
\hline 23 & Linear & MIN/AVG & PROD & BSUM & MOM & 0.290 \\
\hline 24 & Linear & MIN/MAX & PROD & MAX & Fast COA & 0.424 \\
\hline 25 & Linear & MIN/AVG & PROD & MAX & Fast COA & 0.596 \\
\hline 26 & Linear & MIN/MAX & PROD & BSUM & Fast COA & 0.320 \\
\hline 27 & Linear & MIN/AVG & PROD & BSUM & Fast COA & 0.523 \\
\hline 28 & Linear & MIN/MAX & PROD & MAX & Hyper COM & 0.424 \\
\hline 29 & Linear & MIN/AVG & PROD & MAX & Hyper COM & 0.596 \\
\hline 30 & Linear & MIN/MAX & PROD & BSUM & Hyper COM & 0.320 \\
\hline 31 & Linear & MIN/AVG & PROD & BSUM & Hyper COM & 0.523 \\
\hline
\end{tabular}

* $\mathrm{MF}=$ membership function, $\mathrm{MIN}=$ minimum, $\mathrm{MAX}=$ maximum, $\mathrm{PROD}=$ product, $\mathrm{AVG}=$ average, $\mathrm{BSUM}=$ bounded sum, $\mathrm{COM}=$ center of maximum, $\mathrm{COA}=$ center of area. 
Table 4. Results of ergonomic analysis of manual activities in the production line

\begin{tabular}{cccc}
\hline Task & RULA Score & Fuzzy RULA Score & $\begin{array}{c}\text { Back compression from } \\
\text { biomechanical analysis (N) }\end{array}$ \\
\hline Timber setting & 7 & 6.04 & 2829 \\
Nailing 1 & 7 & 6.56 & 3521 \\
Nailing 2 & 7 & 6.04 & 3446 \\
Nailing 3 & 7 & 6.30 & 3479 \\
Nailing 4 & 7 & 5.93 & 1995 \\
Nailing 5 & 7 & 6.30 & 3528 \\
Lifting hole & 6 & 4.88 & 2470 \\
Glue & 7 & 6.63 & 3548 \\
Frame delivery & 4 & 4.12 & 1501 \\
Panel delivery & 2 & 2.22 & 565 \\
Cutting 1 & 3 & 4.45 & 1196 \\
Cutting 2 & 7 & 6.20 & 2145 \\
\hline
\end{tabular}




\section{List of Figures}

Fig. 1. Postures corresponding to data in Table 2

Fig. 2. The impact of upper arm posture categories on intermediate results of Arm \& Wrist score: (a)

Upper arm posture categories of RULA, and (b) abrupt change in RULA Arm \& Wrist score corresponding to change in upper arm angle

Fig. 3. Configuration of a fuzzy logic system

Fig. 4. Structure of the Fuzzy RULA expert system

Fig. 5. Example of point of intersection for upper arm input variable

Fig. 6. Neck, Trunk, \& Leg score table and example of an if-then rule 

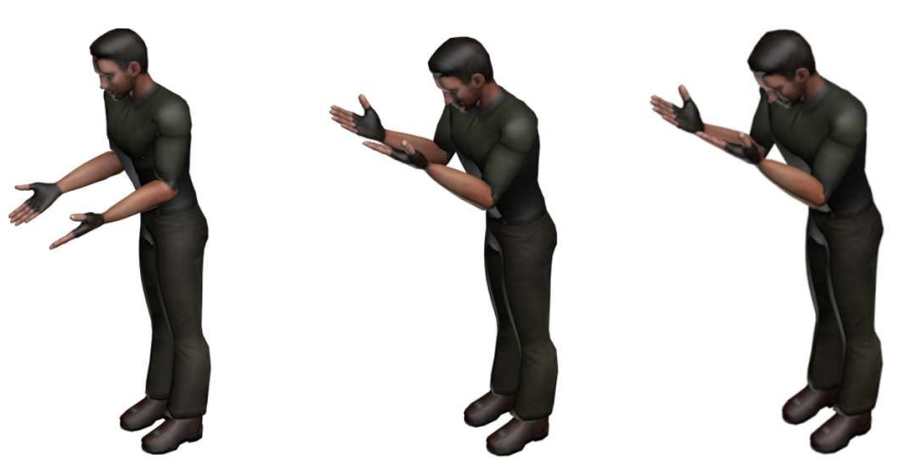

Posture I

Posture II

Posture III

Fig. 1. Postures corresponding to data in Table 2 
Canadian Journal of Civil Engineering

Page 36 of 40

(a)

(b)
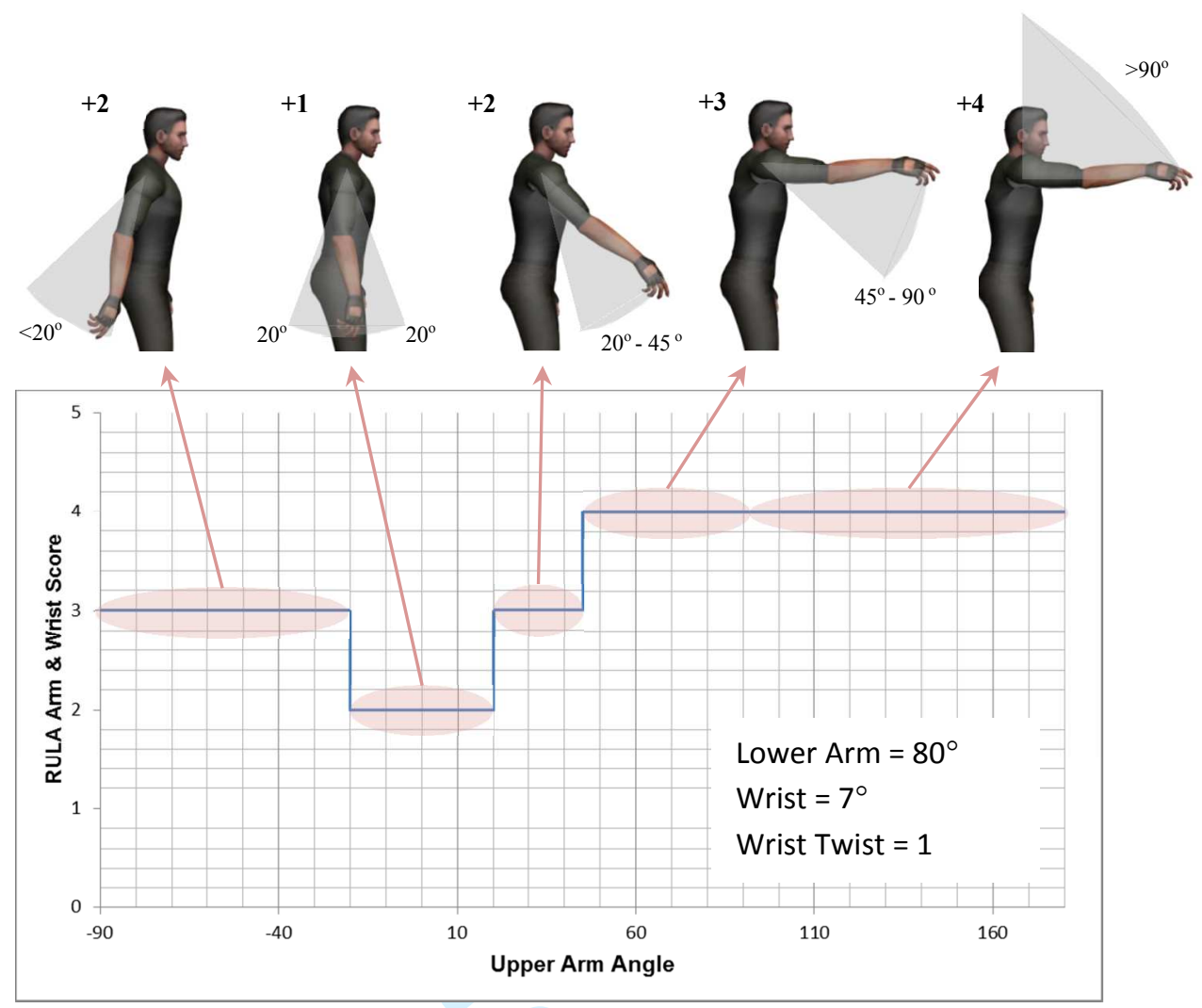

Fig. 2. The impact of upper arm posture categories on intermediate results of Arm \& Wrist score: (a) Upper arm posture categories of RULA (adapted from McAtamney and Corlett (1993), modified from Golabchi et al. (2015)), and (b) abrupt change in RULA Arm \& Wrist score corresponding to change in upper arm angle

https://mc06.manuscriptcentral.com/cjce-pubs 


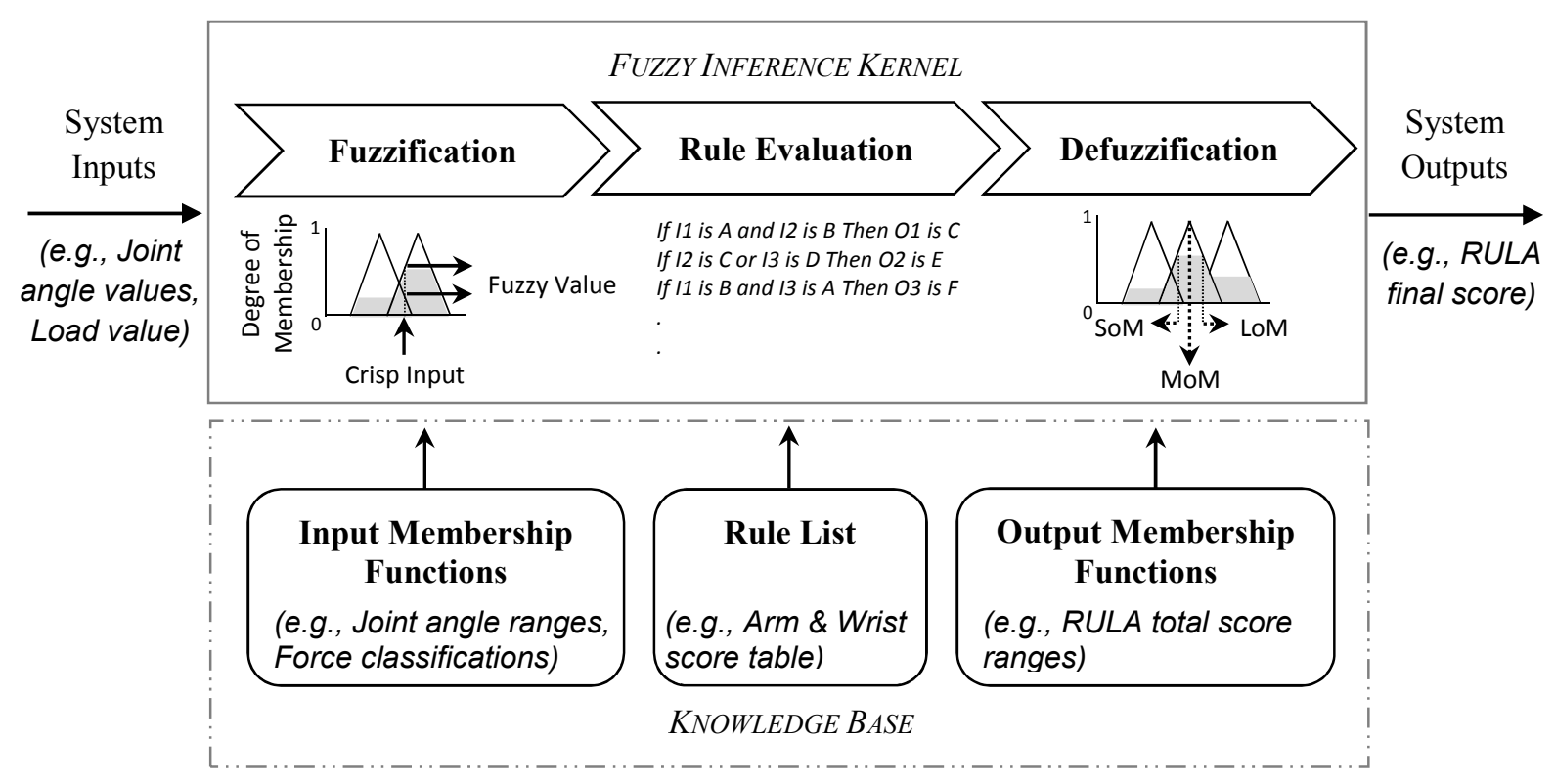

Fig. 3. Configuration of a fuzzy logic system 


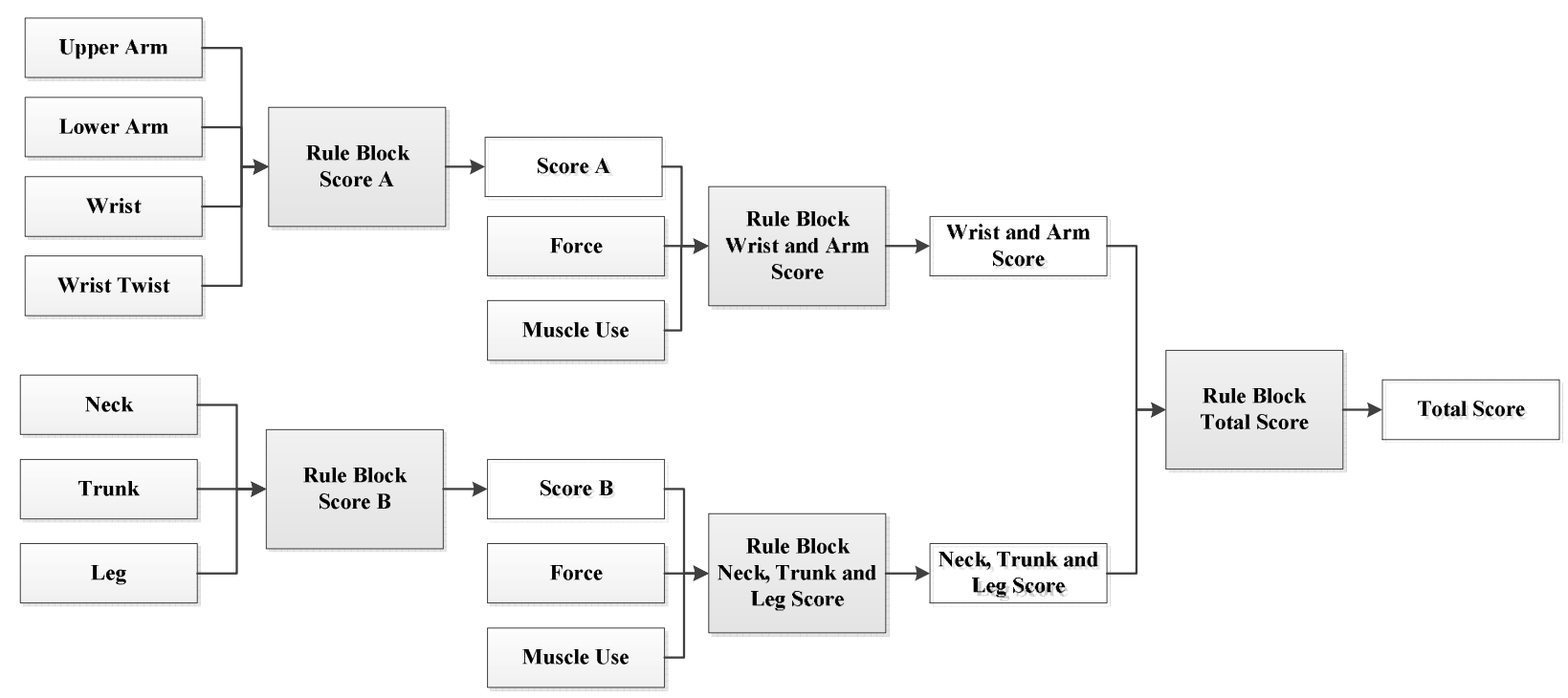

Fig. 4. Structure of the Fuzzy RULA expert system 

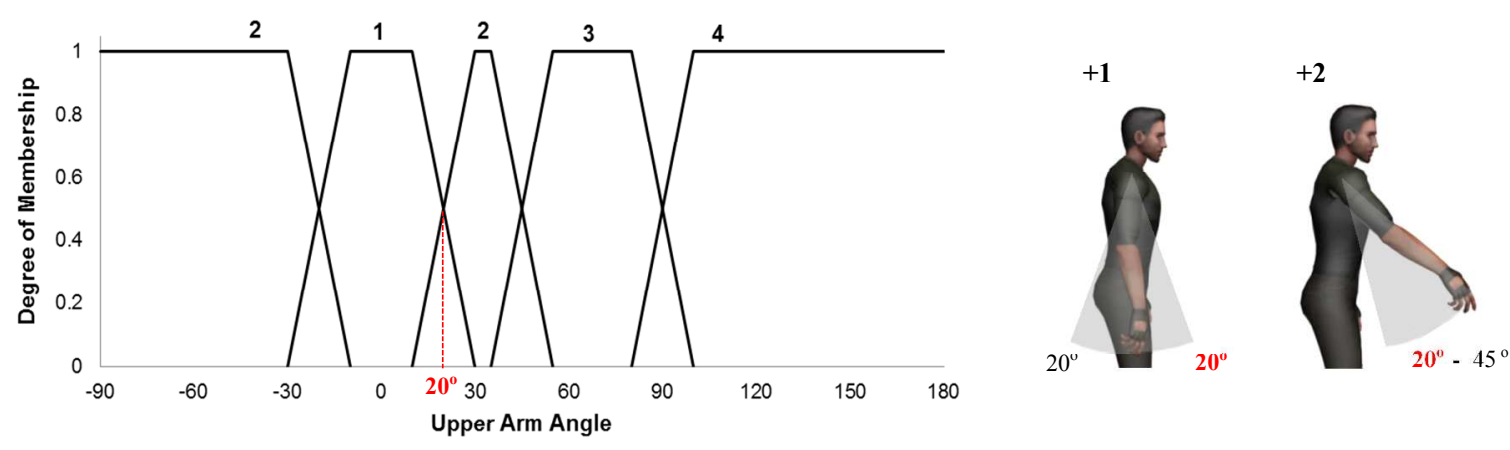

Fig. 5. Example of point of intersection for upper arm input variable 
Trunk Posture Score

\begin{tabular}{|c|c|c|c|c|c|c|c|c|c|c|c|c|c|}
\hline \multirow{3}{*}{$\begin{array}{l}\text { Neck } \\
\text { Posture } \\
\text { Score }\end{array}$} & \multicolumn{2}{|c|}{1} & \multicolumn{2}{|c|}{2} & \multicolumn{2}{|c|}{3} & \multicolumn{2}{|c|}{4} & \multicolumn{2}{|c|}{5} & \multicolumn{2}{|c|}{6} & \\
\hline & \multicolumn{2}{|c|}{ Legs } & \multicolumn{2}{|c|}{ Legs } & \multicolumn{2}{|c|}{ Legs } & \multicolumn{2}{|c|}{ Legs } & \multicolumn{2}{|c|}{ Legs } & \multicolumn{2}{|c|}{ Legs } & \\
\hline & 1 & 2 & 1 & 2 & 1 & 2 & 1 & 2 & 1 & 2 & 1 & 2 & If \\
\hline 1 & 1 & 3 & 2 & 3 & 3 & 4 & 5 & 5 & 6 & 6 & 7 & 7 & (NeckScore) is 2 and \\
\hline 2 & 2 & 3 & 2 & 3 & 4 & 5 & 5 & 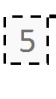 & 6 & 7 & 7 & & $\begin{array}{l}\text { (TrunkScore) is } 4 \text { and } \\
\text { (LegScore) is } 2\end{array}$ \\
\hline 3 & 3 & 3 & 3 & 4 & 4 & 5 & 5 & 6 & 6 & 7 & 7 & 7 & Then \\
\hline 4 & 5 & 5 & 5 & 6 & 6 & 7 & 7 & 7 & 7 & 7 & 8 & 8 & (NeckTrunkLeg) is 5 \\
\hline 5 & 7 & 7 & 7 & 7 & 7 & 8 & 8 & 8 & 8 & 8 & 8 & 8 & \\
\hline 6 & 8 & 8 & 8 & 8 & 8 & 8 & 8 & 9 & 9 & 9 & 9 & 9 & \\
\hline
\end{tabular}

Fig. 6. Neck, Trunk, \& Leg score table and example of an if-then rule 